\section{Native Plants for High-Elevation Western Gardens}

\author{
Janice Busco and Nancy R Morin
}

\author{
Fulcrum Publishing, 16100 Table Mountain Parkway, Suite \\ 300, Golden, Colorado 80403; telephone 800.992.2908; \\ URL: http://www.fulcrum-books.com. Paperback, 352 p, \\ 250 color photos, $18 \times 25 \mathrm{~cm}$ ( $7 \times 10 \mathrm{in}), 2003$, \\ ISBN 1-55591-475-6, US\$ 30.
}

T here has been an explosion of interest in gardening and landscaping with natives, and this attractive book is a contribution to this worthy art and science. The introductory sections provide useful advice for novices on planting and maintaining a native plant garden. These sections reveal that the authors are gardeners themselves and speak from actual experience. Most of the book is devoted to the illustration and discussion of 150 "guaranteed" low-maintenance native plants for the garden. The text associated with each species includes a section called Outstanding Features. For many of the species, this section contains some very useful insights, such as "self-sows and spreads quickly by underground runners" (Oenothera pallida), or "A nonstop bloomer...performs well...in low-maintenance areas like medium strips and parkways" (Penstemon pinifolius). In another section they recommend combinations of species that can be grown together to provide a desired continuity of flowering and color. I especially like the fact that these 2 sections are apparently drawn completely from their gardening experience, presumably at The Arboretum at Flagstaff, Arizona. This is the kind of information that would take the average gardener years to discover by trial and error. A section titled Culture is disappointingly brief, generally consisting of only 1- or 2- word descriptions of soil, exposure, water use, propagation, and care of the species. Most of the rest of the text can be found in any wildflower book. The color photos of each species are generally excellent and it is a plus that most appear to be taken in a garden setting.

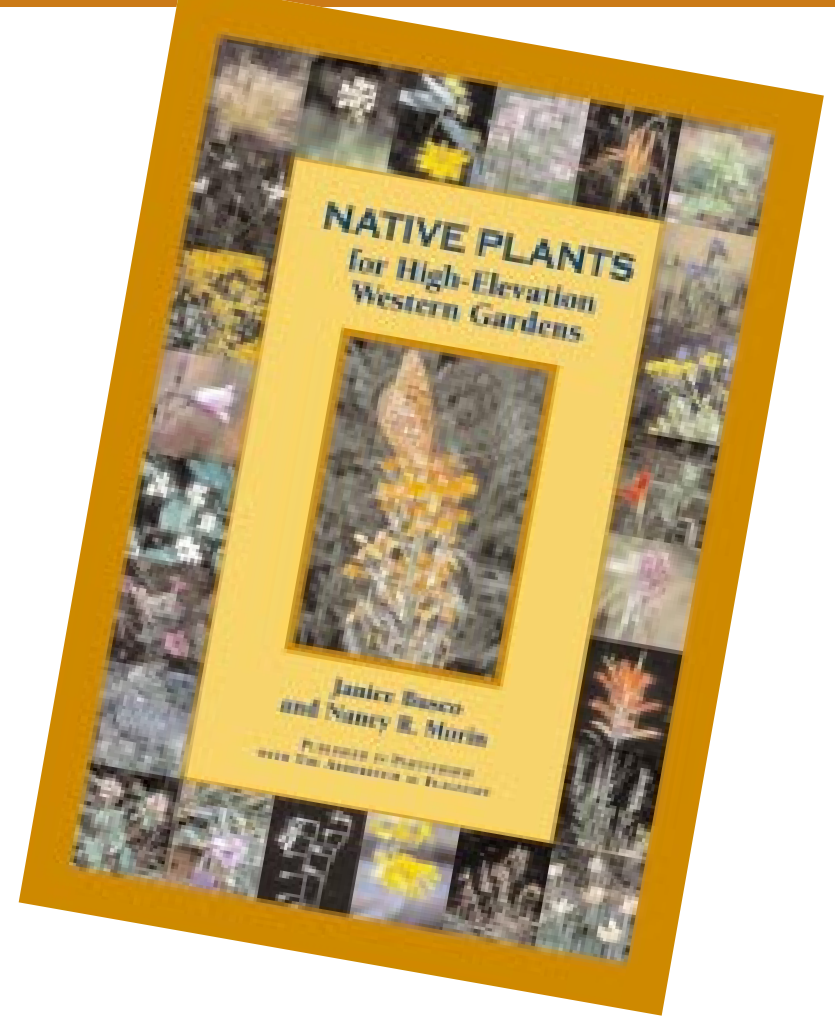

There are a few things of concern, however. First, the term "high elevation" used in the title and throughout the book is not a true ecological classification, which would be the most accurate way to convey where a native species occurs and perhaps where it can be cultivated. For example, the ponderosa pine zone (in which The Arboretum at Flagstaff lies) would not be described as a high-elevation zone anywhere it occurs throughout the West. And, most of the example gardens they cite as high elevation (in places such as Las Vegas and Boise) would be called low elevation by an ecologist. They provide an almost unreadably small plant hardiness zone map for North America, and define zones 1 to 6 as the "High-Elevation West." Inexplicably, they then correctly describe zones 5 and 6 as middle and lower elevation. This fuzziness in the defined scope of the book is further complicated by the fact that the 150 species are drawn predominantly from the southern Rocky Mountains. They feature many interesting southwestern species; the rest of the West is represented by the likes of yarrow and other wide-ranging species. They write about the summer monsoons as a factor in their gardening experiences at Flagstaff, but again this climate is characteristic of the southwest, and nowhere else in the West. Thus, the book has considerable local utility, but perhaps much more limited applicability for gardeners from other regions. I say perhaps because we really don't know about the performance of some of these species in other climates. 
I wish the authors had written more to educate and caution readers about weeds and about what is and isn't a native plant. A plant is truly native only if it evolved in the particular habitat into which it is being planted. It is the existence of native pathogens, parasites, and herbivores that keeps the species in check. Some, perhaps many, of the plants considered in the book grow in the ecosystem represented at The Arboretum at Flagstaff. But many do not, and if they are sown widely, some could well become tomorrow's destructive weeds. It is not an overstatement that invasive weedy species constitute one of the major ecological problems we face. Those who advocate the planting of non-natives bear a serious responsibility. (Yes, most of the 150 species could actually be non-native where they are planted.) Considering that the authors are helping to unleash potential weeds when seed mixes (aka "weeds in a can") are broadcast on someone's acreage, they should have gone way beyond the weak warning buried in their introduction.

\section{Tropical Tree Seed Manual}

\author{
JA Vozzo, Editor \\ USDA Forest Service, Washington DC, Agricultural \\ Handbook Number 721; 899 p; paper; 2002.
}

So, would I recommend the book? If I were gardening in Arizona and immediately surrounding regions, I would consider the book a "must have." Other gardeners who purchase the book will have reason to wonder why the scope of the book has been oversold by adding "High-Elevation" and "Western" to the title.

- Steve Brunsfeld

Steve Brunsfeld is a botanist who is a Professor in the Department of Forest Resources at the University of Idaho. His research interests include plant systematics, biogeography, and conservation genetics. He and his wife, Pam, are avid gardeners and have numerous Rocky Mountain species in cultivation.

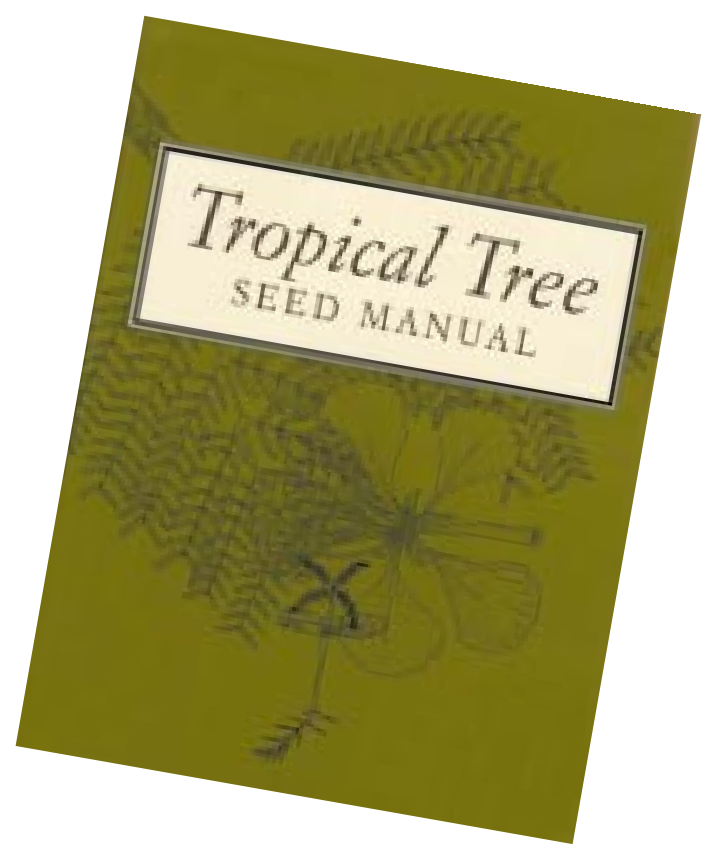

Dendrology" by EL Little Jr — generally is not included in seed manuals. Following Part II is a long list of useful references ( $\mathrm{p}$ 807-860), a glossary, short biographical sketches of the various authors, and indices of common and scientific names.

The longest ( $p$ 13-118), most thorough, chapter in the book is the one by Flores. All aspects of the reproductive biology of angiosperms (relatively little on gymnosperms), that is, micro- and megasporogenesis; embryogenesis; flower, fruit, and seed morphology (also seed anatomy); pollination ecology; seed dispersal; dormancy and germination; and seedling growth and morphology, are discussed in considerable detail. Flores' chapter includes many excellent color photographs and diagrams. Other chapters that I particularly enjoyed reading 
were the ones by Lugo and Zimmerman, and Smith and others. These 3 chapters contain many of the essentials for a course in tropical plant reproductive biology.

Part II contains various types of information on 196 species, (for example, native geographical range, flowering/ fruiting phenology, uses to man, growth habit, habitat, seed biology). Most descriptions are accompanied by drawings of a twig, many of them with flowers or fruits. Seeds and/or seedlings are illustrated for most of the species. Eighteen species (in 4 families) are gymnosperms, and 178 (48 families) are angiosperms. Genera with the most species include Pinus (11), Acacia (7), Quercus (6), and Eucalyptus (5), and families with the most species are Fabaceae (60), Meliaceae (12), Myrtaceae (8), and Euphorbiaceae (7). Of the 196 species, 154 are native to tropical America.

I used information on embryo morphology (that is, underdeveloped versus fully-developed) in fresh seeds from Baskin and Baskin (1998) and seed germination in the Tropical Tree Seed Manual to determine whether seeds of 164 species were dormant or nondormant, and if dormant to which of the 5 dormancy classes each species belongs using the classification system of Baskin and Baskin (1998). Insufficient information for the remaining 32 species precluded any determination of dormancy status. Seeds of 115 of the 164 species, including

\section{S. SUNSHINE
Nursery Propagated Native Plants

WWW.SUNFARM.COM

\author{
Renick, West Virginia, USA 24966 \\ 304.497.2208 • FAX 304.497.2698
}

several legumes, were nondormant (no pretreatment required for seeds to germinate). Of the 49 species whose seeds were dormant (required pretreatment to germinate), 26 had physical dormancy (water-impermeable seed coat); 20 physiological dormancy (low growth potential of embryo); none, except perhaps Acacia mearnsii, combinational dormancy (water-impermeable seed coat and a physiologically-dormant embryo); one, Dendropanax arboreus, morphological dormancy (underdeveloped embryo); and two, Cocos nucifera and Michelia champaca, morphophysiological dormancy (underdeveloped embryo that is physiologically dormant). Sufficient information is given in the manual to indicate that 25 of the 196 species are drying sensitive (recalcitrant). Overall, however, this book contains a rather meager amount of information on the seed biology of the 196 species. Thus, much research remains to be done both on the basic and applied aspects of seeds of economically important forest trees in tropical America. Pulling together what is known about the seed biology of these 196 species is a step in the right direction.

The book is well written, and I found only a very few typos. Further, the physical appearance of this book is excellent with regards to quality of paper, printing, color-photographs, and so on. Anyone interested in seeds and/or in the reproductive biology of tropical trees will want to consult this book. If you can find a copy (a limited printing makes it scarce), handle it carefully. This glue-bound paperback will not hold together with much use; pages in my review copy already are coming loose. Your best bet may be to view it on line at this URL: http://rngr.net/.

- Jerry M Baskin

Jerry M Baskin is Professor of Biology at the University of Kentucky. He has a strong interest in seed dormancy and germination, and he and his wife, Carol C Baskin, have published extensively on the subject.

Baskin CC, Baskin JM. 1998. Seeds: ecology, biogeography, and evolution of dormancy and germination. San Diego (CA): Academic Press. 666p. 